\title{
Evaluation of Anthocorid Predators against Storage Pests of Rice in Assam Situation
}

\author{
D. K. Saikia and R.N. Borkakati* \\ AICRP on Biological Control, Department of Entomology, Assam Agricultural University, \\ Jorhat-785 013, India \\ *Corresponding author
}

\section{Keywords \\ Anthocorid predators, Blaptostethus pallescens, Xylocoris flavipes, Storage pests, $C$. cephalonica}

Article Info

Accepted:

24 July 2020 Available Online: 10 August 2020
Laboratory experiment was conducted to evaluate the efficacy of two important anthocorid predators, Blaptostethus pallescens Poppius and Xylocoris flavipes (Reuter) for the suppression of stored grain pest of rice, Corcyra cephalonica Stainton. Performance of both the anthocorid bug is significant against the infestation of $C$. cephalonica in storage. However, due to smaller size of $X$. flavipes, it was better than $B$. pallescens to enabling them to fit in storage condition. The higher doses of X. flavipes @ 30 nymphs/100 eggs/ jar (12.75-18.00 moths/jar) and 20 nymphs/ 100 eggs/ jar (26.50- 26.75 moths/ jar) were found to be most effective in suppressing the population build-up of $C$. cephalonica in stored rice grain. X. flavipes with respect to nymphal survival was found to be most suitable as higher number of their living nymphs (4.50-14.25 nymphs/ jar) was recovered as compared to $B$. pallescens, where, negligible number of living nymphs (07.70 nymphs/ jar) was recovered. It was concluded that X. flavipes @ 30 nymphs/ jar, followed by X. flavipes @ 20 nymphs/ jar was most effective in controlling $C$. cephalonica in storage of rice grain.

\section{Introduction}

Rice moth, Corcyra cephalonica Stainton (Pyralidae: lepidoptera) is one of the most extensive feeders among the storage pests which feed on a wide variety of cereals, dried vegetable materials, dried fruits like almonds, date palm, nuts, chocolates, biscuits, oilcakes etc in India as well as in other tropical and su btropical regions of the world causing severe economic losses (Adeyemi, 1968; Hodges, 1979). In India, there are about 500 species of insects associated with stored grain products. Among these, nearly 100 species of insect- 
pests of stored product cause economic losses (Kumar, 2015). Shukla and Toke, 2013 reported that more than 20,000 species of field and storage pests causes post-harvest loss of approximately one-third of global food production, valued economically above $\$ 100$ billion per annum. The quantitative and qualitative damage by storage insect pests may vary from $20-30 \%$ in the tropical zone and $5-10 \%$ in the temperate zone (Yankanchi et al., 2014). Anthocorid bugs are important predators amongst different bicontrol agents of C. cephalonica. These, predatory anthocorids are equally effective to control different insect pests including thrips, aphids and mealy bugs in various cropping systems in the Mediterranean Basin and sub-Saharan Africa (Hernandez and Stonedahl, 1999; Sengonca et al., 2008; Zhang et al., 2012; Efe and Cakmak, 2013; Wang et al., 2014). Some indigenous anthocorids identified such as $B$. kumbi Rajasekhara, B. pallescens and Blaptostethus pluto (Distant) are promising biocontrol agents (Rajasekhara 1973; Muraleedharan, 1977; Jalali and Singh, 2002). A considerable amount of information has been generated at the National Bureau of Agricultural Insect Resources (ICAR NBAIR), Bangalore, on the diversity of indigenous anthocorid predators; protocols for mass rearing them have been devised and some potential ones have been successfully evaluated in the field (Ballal et al., 2012). Insect pest management through injudicious application of synthetic chemical pesticides in agriculture is facing several obstacles including, development of pesticide resistance as well as environmental pollution besides human health hazards. Therefore, biological control of crop pests may be an important alternate option for pest management in different crop ecosystems. Several anthocorids species were reported to provide control several pests (Ballal and Yamada, 2016). The predatory bug, $X$. flavipes has been exploited as biological control agents against stored-product pests such as bruchids, moths and mites (Murata et al., 2007; Sing and Arbogast, 2008; Rahman et al., 2009). Similarly, B. pallescens, a general predator with wide host range has also been reported on maize, rose, castor, grapes, bamboo (Jalali and Singh, 2002; Ballal et al., 2003; 2009; Gupta, 2009; Sobhy and Abdul-Hamid, 2014) in India. Blaptostethus pallescens has been identified as a potential bio-control agent for the management of eggs and larvae of lepidopteran pest, sucking pests like mites, thrips, mealybugs, aphids and stored insect pests (Ballalet al., 2009; 2012; Gupta and Ballal, 2011; Lessando et al., 2015; Kaur et al., 2019). From another experiment conducted by Borkakati et al., (2018), found that the highest numbers of predator was proportional to highest yield of crop.

The present study was executed to evaluate the efficacy of anthocorid predators, $B$. pallescensand $X$. flavipes against the stored rice grain moth, $C$. cephalonica.

\section{Materials and Methods}

The experiment was carried out at Biological Control Laboratory, Department of Entomology, Assam agricultural University, Jorhat during 2015-16 and 2016-17 session. The nucleus cultures of $B$. pallescens and $X$. flavipes along with their rearing protocol were supplied by NBAIR, Bengaluru. Mass rearing of both the anthocorids was undertaken in the biocontrol laboratory. The experiment was executed with seven treatments as well as four replications of each treatment under completely randomized block design. One kilogram of untreated rice was taken in plastic jars of two -kilogram capacity for each treatment and each container was infested with 100 numbers eggs of $C$. cephalonica. Seven day old nymphs of the anthocorids @ 10,20 and 30 nymphs per container were released. The treatments were,- T1: Release 
of 10 B.pallescens nymphs; T2: Release of 20 B.pallescens nymphs; T3: Release of $30 \mathrm{~B}$. pallescens nymphs; T4: Release of $10 X$. flavipes nymphs; T5: Release of 20 X.flavipes nymphs; T6: Release of 30 X.flavipes nymphs and T7: Infested grain with no anthocorid predator. The jars were closed along with some pin hole for ventilation and kept at $26 \pm 1^{\circ} \mathrm{C}, \quad 80 \pm 2 \% \quad \mathrm{RH}$ and L14: D10 photoperiod inside the laboratory. Observations recorded on the number of $C$. cephalonica moths $\left(\mathrm{F}_{1}\right)$ and the number of live anthocorid nymphs or adults emerging after a month from each treatment, respectively.

\section{Result and Discussion}

The experiment conducted during 2015-16 indicated that (Table 1) the inoculated release of X.flavipes @ 30 nymphs per kg of stored rice (12.75 moths/ container) was significantly superior to all other treatments in reducing the emergence of $C$. cephalonica moths. In untreated control mean number of emergence of $C$. cephalonica was 70.25. However, all the treatments showed comparatively better results in reducing the emergence of $C$. cephalonica moths while compared to untreated control. Maximum number of living nymphs was recorded from the treatment of $X$. flavipes @ 30 nymphs/ container (14.25) followed by X. flavipes @ 20 nymphs/ container (9.50), whereas comparatively less number of living nymphs was observed in different treatments of $B$. pallescens, the maximum average emergence of living nymphs (7.70) was found in the treatment with 30 nymphs of $B$. pallescens.

The same experiment was also conducted again during 2016-17 for confirmatory trial revealed that (Table 1) the inoculative release of X.flavipes @ 30 nymphs per kg of stored rice $(18.00$ moths/ container $)$ was significantly superior to all other treatments in reducing the emergence of $C$. cephalonica moths. However, B pallescens @ 30 nymphs/container and X. flavipes @ 10 nymphs / container were on par with each other (32.5 and 36.0 moth emerged respectively) in infested stored rice. On an average, the moth emergence in untreated control was 59.25. Maximum number of living nymphs was recorded from the treatment of X.flavipes @ 30 nymphs/ container (12.50) followed by X. flavipes @ 20 nymphs/ container (7.75), whereas negligible number of living nymphs was observed in different treatments of $B$. pallescens, the maximum average emergence of living nymphs (1.25) was found in the treatment with 30 nymphs of $B$. pallescens.

From the investigation carried out by Brower and Mullen (1990) and Brower and Press (1992) also revealed that the usefulness of $X$. flavipes as a component in integrated pest management programme of moths in peanut storage and empty corn bins. The negligible number of living $B$. pallescens might be due to the fact that $B$. pallescens can lay eggs only on plant material, while, $X$. flavipes can lay eggs on plain surfaces or on cotton (Ballal et al., 2003). LeCato and Davis (1973) reported that small size of $X$. flavipes enables them to move freely in stored grain. Further, unavailability of surviving and preferred stages of $C$. cephalonica eggs may lead to cannibalism amongst $X$. flavipes and results minuscule recovery of bioagent (Kaur and Virk, 2011). However, natural population of this predator is insufficient to maintain the target pest population below economic injury levels on several crops. Therefore, mass production and augmentative releases of natural enemies may help to maintain some of the target pests below economic injury levels (Gupta et al., 2018). It was, therefore, concluded from the experiment that $X$. flavipes was better than $B$. pallescens in controlling $C$. cephalonica moth infestation in stored rice in the laboratory condition. 
Table.1 Effect of anthocorid predators against storage pests of rice (2015-16 and 2016-17)

\begin{tabular}{|c|c|c|c|c|}
\hline \multirow[t]{2}{*}{ Treatments } & \multicolumn{2}{|c|}{$\begin{array}{l}\text { Mean no. of } \\
\text { C. cephalonica moth } \\
\text { emergence* }\end{array}$} & \multicolumn{2}{|c|}{$\begin{array}{l}\text { Mean no. of living } \\
\text { anthocorids (nymphs)* }\end{array}$} \\
\hline & 2015-16 & 2016-17 & 2015-16 & 2016-17 \\
\hline Blaptostethus pallescens@10 nymphs & $61.75^{\mathrm{b}}$ & $55.75^{\mathrm{a}}$ & 0 & $\mathbf{0}$ \\
\hline Blaptostethus pallescens@20nymphs & $53.25^{\mathrm{c}}$ & $41.25^{\mathrm{b}}$ & $5.50^{\mathrm{d}}$ & $0.75^{d}$ \\
\hline Blaptostethus pallescens@30 nymphs & $46.75^{\mathrm{d}}$ & $32.5^{\mathrm{c}}$ & $7.70^{c}$ & $1.25^{d}$ \\
\hline Xylocoris flavipes@10 nymphs & $38.50^{\mathrm{e}}$ & $36.0^{c}$ & $6.75^{\mathrm{cd}}$ & $4.50^{c}$ \\
\hline Xylocoris flavipes@20 nymphs & $26.50^{\mathrm{f}}$ & $26.75^{\mathrm{d}}$ & $9.50^{b}$ & $7.75^{b}$ \\
\hline Xylocoris flavipes@30 nymphs & $12.75^{\mathrm{g}}$ & $18.00^{\mathrm{e}}$ & $14.25^{\mathrm{a}}$ & $12.50^{\mathrm{a}}$ \\
\hline Untreated & $70.25^{\mathrm{a}}$ & $59.25^{\mathrm{a}}$ & 0 & $\mathbf{0}$ \\
\hline S. Ed $\mathbf{E}$ & 9.30 & 2.34 & 24.40 & 0.58 \\
\hline $\mathbf{C V}$ & 4.32 & 4.91 & 1.52 & 1.22 \\
\hline CD at $5 \%$ & & 8.75 & & 21.55 \\
\hline
\end{tabular}

\section{Acknowledgement}

The authors are grateful to the Director of NBAIR, Bengaluru for the necessary funding for the experiment. The authors are also indebted to the Director of Research (Agri), Assam Agricultural University, Jorhat-785 013 for their help and suggestion during the course of the investigation.

\section{References}

Adeyemi, S.A.O.1968. A laboratory study of competition between Tribolium castaneum Hbst. (Coleoptera: Tenebrionidae) and three moth species. Bulletin of Entomological Research, 58: 31-45.

Ballal CR, Singh SP, Poorani J, Gupta T.
2003. Biology and rearing requirements of an anthocorid predator, Blaptostethus pallescens (Poppius). Journal of Biological Control, 17:29-33.

Ballal CR, Gupta T, Joshi S, Chandrashekhar K. 2009. Evaluation of an anthocorid predator Blaptostethus pallescens against two-spotted spider mite, Tetranychus urticae. IOBC/WPRS Bull.49: 127-32.

Ballal CR, Gupta T, Joshi S. 2012. Predatory potential of two indigenous anthocorid predators on Phenacoccus solenopsis Tinsley and Paracoccus marginatus Williams and Granara de Willink. Journal of Biological Control, 26: 1822.

Ballal CR, Yamada K.2016. Antocorid predator. In: pp. 329-366. Omkar (Ed.). 
Ecofriendly pest management for food security Elsevier, London 727 pp.

Borkakati, R. N., Saikia, D. K., Buragohain, P.2018. Natural enemy fauna of agrihorti ecosystem of Assam. Indian Journal of Entomology. 80(3): 658-661

Brower, J. H. and Mullen, M. A.1990. Effects of Xylocoris flavipes (Hemiptera: Anthocoridae) releases on moth populations in experimental peanut storages. Journal of Entomological Science, 25: 268-276.

Brower, J. H. and Press, J. W. 1992. Suppression of residual populations of stored - product pests in empty corn bins by releasing the predator Xylocoris flavipes (Reuter). Biological Control, 2: 66-72.

Efe D, Cakmak I. 2013. Life table parameters and predation of Oriusniger (Wolf) (Hemiptera: Anthocoridae) feeding on two different prey. Turkish Journal of Entomology, 37: 161-67.

Gupta T, Ballal C R and Kadam S S. 2018.Morphology and performance specifications of Blaptosthethus pallescens Poppius (Heteroptera: Anthocoridae) when reared on two alternate laboratory hosts. Journal of Biological Control, 32(4): 239-245, DOI: $10.18311 / \mathrm{jbc} / 2018 / 19907$

Gupta T, Ballal CR. 2011. Preferential feeding potential of an anthocorid predator Blaptostethus pallescens Poppius on different stages of cotton mealybug. Journal of Environmental Entomology, 33(4): 423-428.

Gupta T. 2009. Studies on production and utility of anthocoridpredators- with special reference to Orius spp. and Blaptostethus spp. Ph.D thesis submitted to Mysore University, 207.

Hernandez LM, Stonedhal GM. 1999. A review of economically important species of genus Orius and Oriussauteri (Hemiptera: Antocoridae) when reared on Ephestia kuehinella eggs. Applied Entomology and Zoology, 33: 449-53. https://doi.org/10.1080/0022293993002 45

Hodges, R.J., 1979, A review of the biology and control of the rice moth Corcyra cephalonica Stainton. Rep. Trop. Prod. Inst. No. G 125, pp. 20.

Jalali SK, Singh SP. 2002. Seasonal activity of stem borers and their natural enemies on fodder maize. Entomon, 27: 137-46.

Kaur R and Virk J P. 2011. Role of Blaptostethus pallescens Poppius and Xylocoris flavipes (Reuter) in the suppression of C. cephalonica cephalonica Stainton in stored rice grain. Journal of Biological Control, 25 (4): 329-332

Kaur R, Sharma S, Shera P S and Sangha K S. 2019. Evaluation of anthocorid predator, Blaptostethus pallescens Poppius against spider mite, Tetranychus urticae Koch on Okra under insect net cage condition. Journal of Biological Control, 33(3): 236-241, 2019, DOI: $10.18311 / \mathrm{jbc} / 2019 / 16283$

Kumar N. 2015.CaesuliaaxillarisRoxb. Leaf oil-A potential alternate of synthetic pesticides for protecting seeds of groundnut during storage. International Journal Current Microbiology Applied Sciences, 4:372-83.

LeCato, G. L. and Davis, R. 1973. Preferences of the predator Xylocoris flavipes (Hemiptera: Anthocoridae) for species and instars of stored - product insects. Florida Entomologist, 56: 5759.

Lessando M. Gontijo, DaianeCelestino, Obiratanea S. Queiroz, Raul Narciso C. Guedes, Marcelo C. Picanço. 2015. Impacts of azadirachtin and chlorantraniliprole on the developmental stages of pirate bug predators (Hemiptera: Anthocoridae) of the tomato pinworm Tutaabsoluta 
(Lepidoptera: Gelechiidae). Florida Entomologist, 98(1). https://doi.org/10.1653/024.098.0111

Muraleedharan N. 1977. Some genera of Anthocorinae (Heteroptera: Anthocoridae) from South India. Entomon, 2: 231-35.

Murata, M., Imamura, T. and Miyanoshita, A. 2007. Suppression of stored- product insect Tribolium confusum by Xylocoris flavipes and Amphibolus venator. Journal of Applied Entomolgy, 131: 559-563.

Rahman, M. M., Islam, W. and Ahmed, K. N. 2009. Functional response of the predator Xylocoris flavipes to three stored product insect pests. International Journal of Agriculture and Biology, 11: 316-320.

Rajasekhara K. 1973. A new species of Blaptostethus (Hemiptera: Anthocoridae) from Mysore, India. Annals of the Entomological Society of America,66: 86-87. https://doi.org/10.1093/aesa/66.1.86

Sengonca C, Ahmadi K, Blaeser P. 2008. Biological characteristics of Oriussimilis Zhang (Heteroptera: Anthocoridae) by feeding on different aphid species as prey. Journal of Plant Diseases and Protection, 115: $\quad 32-38$. https://doi.org/10.1007/BF03356236

Shukla A, Toke NR. 2013. Plant products as a potential stored product insect management agents. Indian Journal of Research, 2:4-6.
Sing, S. E. and Arbogast, R. T. 2008. Optimal Xylocoris flavipes (Reuter) (Hemiptera: Anthocoridae) density and time of introduction for suppression of bruchid progeny in stored legumes. Environmental Entomology, 37: 131142.

Sobhy I S and Abdul-Hamid A M.2014. Life history traits of Blaptostethus pallescens (Hemiptera: Anthocoridae), a candidate for use in augmentative biological control in Egypt. Applied Entomology and Zoology, 49:315-324

Wang S, Michand JP, Tan XL, Zhang F. 2014. Comparative suitability of aphids, thrips and mites as prey for the flower bug Oriussauteri (Hemiptera: Anthocoridae). European Journal of Entomology, 111: 221-26. https://doi.org/10.14411/eje.2014.031

Yankanchi SR, Jadav AD, Patil PM. 2014. Insecticidal and repellent activities of Clerodendrun serratum L. leaf extract against rice weevil, Sitophiluus oryzae L. Asian Journal of Biological and Life sciences, 3:35-39.

Zhang SC, Zhu F, Zheng XL, Lei CL, Zhou XM. 2012. Survival and developmental characteristics of predatory bug, Oriussimilis (Hemiptera: Anthocoridae) fed on Teteranychus cinnabarinus (Acari: Tetranychidae) at three constant temperatures. European Journal of Entomology, 109: 503-08. https://doi.org/10.14411/eje.2012.063

\section{How to cite this article:}

Saikia, D.K. and Borkakati, R.N. 2020. Evaluation of Anthocorid Predators against Storage Pests of Rice in Assam Situation. Int.J.Curr.Microbiol.App.Sci. 9(08): 3180-3185. doi: https://doi.org/10.20546/ijcmas.2020.908.362 